\title{
Memória Viva de Árabes na Fronteira: Aspectos da Cultura e Religiosidade
}

\author{
Memoria Viva de Árabes en la Frontera: Aspectos de la Cultura y \\ la Religiosidad
}

Memory of Arabs at the Border: Aspects of Culture and Religiosity

\author{
Dalal Jamal Yousef Dawas ${ }^{1}$ \\ Me. Alessandra Buriol Farinha ${ }^{2}$
}

\begin{abstract}
Resumo
Este trabalho tem como objetivo principal analisar e registrar aspectos da cultura árabe presentes na fronteira, tais como religiosidade, gastronomia, folclore, indumentária, dentre outros. O trabalho tem como motivação a visibilidade da identidade árabe na fronteira buscando entender como esses povos vieram e quais impactos positivos e negativos que sentiram ao estarem na fronteira Brasil/ Uruguai, especificamente em Jaguarão/Rio Branco. É de suma importância a valorização da identidade, o sentimento de pertencimento ao país de origem, e as práticas culturais que fazem com que esses povos sintam sua nação presente mesmo no país de imigração. A prática cultural propicia a constituição de conhecimentos tais como crenças, hábitos, tradições e fazem com outros povos de outras nacionalidades presentes na fronteira desenvolvam relações sociais com o aprendizado de novas culturas. Para isso é necessário que se desenvolva o conceito de alteridade que é fundamental na unidade e respeito entre os habitantes de um determinado local e nas diferenças culturais e religiosas da sociedade A metodologia utilizada foi análise de referências teóricas acerca da diáspora árabe no Rio Grande do Sul, observação de campo e entrevistas semi-estruturadas com dois descendentes de árabes na cidade de Jaguarão.
\end{abstract}

Palavras-Chave: Cultura Árabe, Identidade, Fronteira, Memória.

Resumen

Este trabajo tiene como objetivo principal analizar y registrar aspectos de la cultura árabe presentes en la frontera, tales como religiosidad, gastronomía, folclore, indumentaria, entre otros. El trabajo tiene como motivación la visibilidad de la identidad árabe en la frontera. El trabajo también busca entender cómo esos pueblos vinieron y qué impactos positivos y negativos que sintieron al estar en la frontera Brasil / Uruguay, específicamente en Jaguarão / Rio Branco. Es de suma importancia la valorización de la identidad, el sentimiento de pertenencia al país de origen, y las prácticas culturales que hacen que esos pueblos sientan su nación presente en el país de inmigración. La práctica cultural propicia la constitución de conocimientos tales como creencias, hábitos, tradiciones y hacen con otros pueblos de otras nacionalidades presentes en la frontera desarrollar relaciones sociales con el aprendizaje de nuevas culturas. Para ello es necesario que se desarrolle el concepto de alteridad que es fundamental en la unidad y respeto entre los habitantes de un determinado lugar y en las diferencias culturales y religiosas de la sociedade. La metodología utilizada fue el análisis de referencias teóricas acerca de la diáspora árabe en Rio Grande do Sul, observación de campo y entrevistas semiestructuradas con dos descendientes de árabes en la ciudad de Jaguarão.

Palabras claves: Cultura Árabe, Identidad, Frontera, Memoria

\footnotetext{
${ }^{1}$ Graduanda em Tecnologia e Gestão do turismo na Universidade Federal do Pampa, Campus Jaguarão, Rio Grande do Sul, Brasil; dalal.dawas@ @otmail.com

${ }_{2}$ Mestra em Memória Social e Patrimônio Cultural. Docente na Universidade Federal do Pampa, Campus Jaguarão, Rio Grande do Sul, Brasil; alessandrafarinha@unipampa.edu.br
} 


\begin{abstract}
This work has as main objective to analyze and register aspects of the Arab culture present in the frontier, such as religiosity, gastronomy, folklore, clothing, among others. The work is motivated by the visibility of the Arab identity on the border. The work also seeks to understand how these peoples came and what positive and negative impacts they felt when they were on the Brazil / Uruguay border, specifically in Jaguarão / Rio Branco. The value of identity, the sense of belonging to the country of origin, and the cultural practices that make these people feel their nation present even in the country of immigration is of paramount importance. Cultural practice promotes the formation of knowledge such as beliefs, habits, traditions and other people of other nationalities present at the border develop social relations with the learning of new cultures. For this, it is necessary to develop the concept of alterity that is fundamental in the unity and respect between the inhabitants of a certain place and in the cultural and religious differences of the society. The methodology used was analysis of theoretical references about the Arab diaspora in Rio Grande do Sul, field observation and semi-structured interviews with two descendants of Arabs in the city of Jaguarão.
\end{abstract}

Keywords: Arabic Culture, Identity, Border, Memory

\title{
1. Introdução
}

Este trabalho tem como principal objetivo analisar a cultura e identidade árabe na fronteira, especificamente entre Jaguarão, Brasil e Rio Branco, Uruguai, registrando alguns dos bens culturais legados por antepassados, visando assim apresentar aspectos religiosos, folclóricos e culturais e além de relacionar algumas práticas desenvolvidas na fronteira tanto como no país de origem, o que se mantem presente da tradição.

A principal justificativa de ter escolhido este tema foi o fato de saber mais sobre antepassados da família da autora Dalal Dawas, rememorando aspectos da diáspora, como eles vieram para fronteira, motivo que os fez escolher o sul do Brasil, a fronteira aqui representada pelos municípios de Jaguarão, Brasil/Rio Branco, Uruguai e, além disso, esse tema é fundamental para a compreensão da identidade local.

Assim, acredita-se que é importante a contextualização desses dados, o registro de bens culturais deixados por eles para que as futuras gerações possam entender quem eles são, qual é a sua identidade e principalmente, como acontece a manutenção desta identidade, visto que são imigrantes e descendentes deles que não tem lugares específicos para manifestar sua cultura, para suas festas, para suas rezas e diversos outros rituais coletivos.

Este trabalho traz breve contextualização acerca da diáspora árabe na fronteira, citando principalmente Jardim (2017). Aborda também parte da história da imigração árabe em Jaguarão, elencando alguns estranhamentos, impactos positivos e negativos que os árabes entrevistados vivenciaram ao chegarem na fronteira Jaguarão / Rio Branco. Na análise dos dados, traz questões da religiosidade, explicando como se dá a prática da religião, quais são suas práticas na fronteira, como exemplo o Ramadã, que significa a prática do jejum, a questão do natal, relatando aspectos de como ele é celebrado pelos árabes na fronteira, relacionado com suas práticas em países árabes que é a principal origem da atividade. 
Para a realização desse trabalho além de pesquisa bibliográfica tendo como base autores referentes ao tema, foi feita observação de campo de agosto a novembro do corrente ano e entrevistas semi-estruturadas com descendentes de árabes na cidade de Jaguarão. As entrevistas com 02 depoentes descendentes de árabes, moradores da fronteira, ocorreram nos meses de setembro e outubro de 2017. Os depoentes foram escolhidos mediante contatos familiares da autora Dalal Dawas e entrevistados em suas próprias residências em Jaguarão, mediante agendamento prévio. A lista de questionamentos feita para os depoentes encontra-se no final deste artigo. Foi feito também o registro fotográfico de algumas das atividades para que o objeto de estudo fique mais coerente e acessível para quem tem o interesse de conhecer a memória e identidade árabe na fronteira.

Com a realização deste trabalho foi possível compreender as dificuldades enfrentadas pelos imigrantes em meados do século XX, a importância da vivência coletiva de valores e costumes, de lugares de celebração, para que se mantenha a identidade.

\section{A imigração árabe em Jaguarão, na Fronteira Brasil /Uruguai}

Segundo a história de registros orais e das pessoas entrevistadas a imigração árabe no Brasil ocorreu em momentos diferentes de histórias e períodos, mas principalmente entre o final do século XIX é início do século XX até a Segunda Guerra Mundial. Nesta época, em 1948 na Palestina ocorria uma guerra civil, o que motivou a imigração desses povos para outros países, principalmente ao Brasil em países da fronteira.

Outra questão que ocasionou a imigração desses povos foi uma crise econômica e política que ocorria em territórios árabes, ou seja, muitos deles vieram para as fronteiras por melhores condições de vida e estabilidade financeira já que tiveram seu local de origem arrasados com a guerra que teve que acabou com elementos culturais, mesquitas, monumentos, dentre outros que esses povos tinham no país de origem.

De acordo com o depoente Radi Abu Saleh, de 71 anos, que chegou no Brasil na década de 1960: "a vida do imigrante é difícil. Às vezes os imigrantes vêm com cinquenta anos e começam a trabalhar como tivessem quinze anos, para poder construir sua vida". O depoente, atualmente com a situação econômica estável, recorda das dificuldades em começar a vida, se estabelecer em um país distante.

Jardim (2017) afirma que essa imigração que ocorreu permitiu que mais tarde, ao longo do tempo, esses povos trouxessem suas famílias para o Brasil já como principal objetivo sua permanência definitiva no país. Com sua permanência esses imigrantes vieram para as fronteiras e começaram a desenvolver suas primeiras atividades. De forma geral, a 
primeira atividade que realizaram foi o ofício de mascate, pois essa profissão não necessitava domínio da língua portuguesa e espanhola e também não necessitava de recursos e de estudos. Uma característica desses povos é a questão da negociação do comércio, o que torna o trabalho mais valorizado. $\mathrm{Na}$ fronteira, o comércio tem características múltiplas, com diferentes públicos e possibilidades.

A dualidade dos espaços de fronteira é uma característica bastante evidente, explicitada, de um lado, pela necessidade de se estabelecer separações e limites, em nome de uma diferença cultural e da preservação da soberania nacional e, de outro lado, pelas práticas sociais e trocas que, em face da proximidade física e dos interesses comuns, se estabelecem. A fronteira é, a um só tempo, área de separação e de aproximação, linha de barreira e espaço polarizador. É, sobretudo, um espaço de tensões, de coexistência das diferenças, e do estabelecimento de novas realidades socioculturais. (CASTELLO, 1995, p. 18).

Conforme afirma Castello (1995), o espaço de fronteira ao mesmo tempo em que representa uma separação e um limite ele se integra e sintetiza o que pode-se chamar de hibridismo. Na fronteira também se percebe a diversidade da cultura e religiosidade.

De acordo com Aseff (2014), os árabes e os seus descendes que chegaram ao o Rio Grande do Sul, vieram para a fronteira através de navios que geralmente demoravam cerca de três meses para chegar ao local de destino e eram recebidos por familiares ou amigos que já estavam aqui. Os primeiros palestinos chegaram em 1948 e também na década posterior. Ao chegarem eles tiveram contato com a região fronteiriça onde houve a diversidade de cultura entre a fronteira e esses imigrantes, pois ao mesmo tempo em que eles mantinham contato com outras culturas a fronteira teve contato com a cultura e comunidade árabe e suas práticas culturais desenvolvidas aqui.

Hannerz (1997, p. 08) afirma que o hibridismo é observado quando uma coletividade de outra nação está fora de sua terra natal esses povos tentam organizar suas formas de cultura e tentam adapta-la ao país que estão vivendo, pois existem elementos que não estão presentes no país de imigração. É sobre assa adaptação que iremos discorrer.

De acordo com Mazzei (2010) a valorização da cultura híbrida é de suma importância para a construção de uma identidade e também ao sentimento de pertencimento das pessoas, a questão do hibridismo na cultura é fundamental principalmente em países de fronteira ,onde a questão da mistura de culturas predomina. 


\section{Registro de manifestações culturais Árabes em Jaguarão, Brasil}

A importância de manter a cultura viva, os laços sociais, a memória, e a identidade são fundamentais para a compreensão da origem das pessoas e também para que as nova gerações possam entender como seus antepassados viviam e praticavam suas atividades culturais e religiosas. De acordo com Assmann (2006), na memória comunicativa, ou geracional, o ente mais velho relembra o que lhe foi ensinado por seu avô e transmite esses ensinamentos, enriquecidos pela sua experiência, para seu neto. A teoria da memória geracional nos ajuda a compreender como as tradições são, de certa forma, selecionadas pelas pessoas, como elas são hierarquizadas, consideradas importantes e que, portanto, merecem ser transmitidas para os seus.

Supostamente, as tradições árabes que existem na fronteira passaram por essa seleção. São elementos escolhidos para serem transmitidos às futuras gerações, porém as vezes sem a presença do ancião, conforme afirma Assmann (2006), na memória comunicativa ou geracional. Possivelmente a condição de imigrantes não permitiu esta transmissão, essa comunicação avô-neto, papel que foi atribuído aos pais que constituíram a vida no Brasil.

De acordo com Simão (2006, p. 15), a preservação dos valores culturais reveste a importância das manifestações culturais do passado que vão sendo passada por gerações. Evidentemente em um passado recente a cultura árabe não tinha representação na fronteira entre Brasil e Uruguai, especificamente em Jaguarão, porém, após a diáspora, é preciso refletir acerca do conhecimento e valorização desta cultura em tempos hodiernos.

A discussão sobre o que deve ser preservado e legitimado como um patrimônio é recorrente e uma disputa que envolve, geralmente as classes dominantes, de elite e as classes historicamente discriminadas.

\footnotetext{
Indagações sobre quem tem legitimidade para selecionar o que deve ser preservado, a partir de que valores, em nome de que interesses e de que grupos, passaram a pôr em destaque a dimensão social e política de uma atividade que costuma ser vista como eminentemente técnica. Entendia-se que o patrimônio cultural brasileiro não devia se restringir aos grandes monumentos, aos testemunhos da história oficial, em que sobretudo as elites se reconhecem, mas devia incluir também manifestações culturais representativas para os outros grupos que compõem a sociedade brasileira - os índios, os negros, os imigrantes, as classes populares em geral (FONSECA, 2001, p. 112).
}

Essa democratização do reconhecimento de diversos patrimônios nacionais, manifestações culturais que têm no seu cerne as mais diversas nacionalidades, faz com que a tolerância, a pacificidade, o conhecimento, o intercâmbio sejam possíveis. $\mathrm{Na}$ fronteira mencionada, em Jaguarão, são presentes diversos traços da cultura árabe, porém em trabalhos 
acadêmicos, não foram encontrados registros, pesquisas sobre os elementos e a compreensão de significados, a história, a memória desta comunidade. Assim, esse trabalho busca reduzir essa lacuna, com relatos, registros fotográficos e descrição sobre a religiosidade, gastronomia e indumentária árabe em Jaguarão.

\subsection{Religiosidade}

De acordo com depoimentos, com a permanência desses povos na fronteira ocorreu o desenvolvimento de suas manifestações culturais mesmo estando fora de sua terra de origem. Por exemplo, na questão da religião, a realização das rezas e do Ramadã se manteve presente da cultura árabe na fronteira. No caso de Jaguarão, as depoentes afirmam que a realização das rezas é feita nas residências por não existir uma mesquita no local. Também às vezes existem reuniões de rezas onde todos oram juntos e no mês do Ramadã, as pessoas convidam os amigos e familiares para jantarem juntos.

O depoente Radi Abu Saleh afirma: “[...] quando eu vim para a fronteira tinha uma sociedade Palestina aqui onde existia escolas, aulas de religião, mas acabou durando pouco por aceitação dos mais velhos”. O depoente faz menção à sociedade palestina, que era um dos lugares de encontro e socialização da comunidade árabe em Jaguarão. Durante a entrevista, foi possível perceber certa lástima do depoente pelo fechamento da sociedade. A Figura 01 é o prédio onde funcionava a antiga Sociedade Palestina, localizada em Jaguarão. O prédio se situa à rua 15 de novembro número 596, na esquina com a rua Barbosa Neto e atualmente encontra-se fechado.

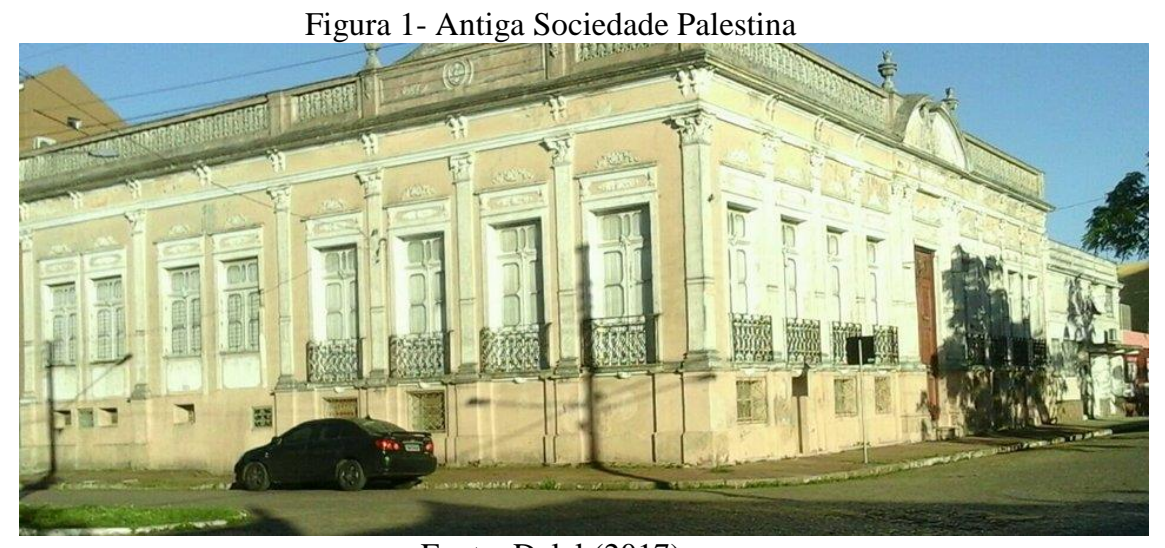

Fonte: Dalal (2017)

De acordo com Costa e Gastal (2010) a questão da construção de uma mesquita em Jaguarão e também em outros lugares da fronteira representa a mudança da paisagem da 
fronteira pela presença de imigrantes árabes e seus descendentes. Essas edificações darão suporte à imaterialidade dos fazeres culturais como a práticas de rezas, festas, cerimônias, dentre outras. Na Figura 02, encontra-se a fotografia da Mesquita que está sendo construída no Chuí, município que faz fronteira com o Chuy no Uruguai, extremo sul do Brasil.

\section{Figura 2- Construção da Mesquita Chuí}

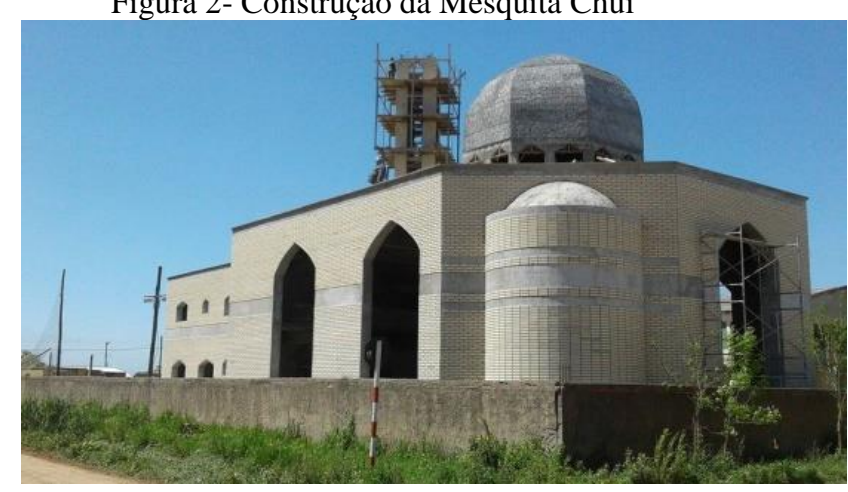

Fonte: Abu Ammar (2017)

\subsection{Rezas Árabes}

Mesmo que não seja aconselhável fazer generalizações em trabalhos acadêmicos, pode-se afirmar que a religiosidade é uma característica marcante do povo árabe. De acordo com Hayeh (1989, p.7) as práticas culturais e a questão da construção de uma comunidade árabe em países de imigração é de suma importância para a questão do pertencimento da cultura e da religião presente na vida das pessoas. Em Jaguarão, conforme dito, não há mesquita, mas os preceitos da fé são seguidos pelas famílias descendentes de árabes, como exemplo disso as rezas e o Ramadã.

A depoente Khawla Daous afirma que aprendeu a religião e a rezar com sua mãe e passou para os filhos, como também a questão do Ramadã. A depoente relata que por isso esses aspectos se mantiveram vivos na fronteira, mesmo estando fora de sua terra natal. Um exemplo de oração comum entre os árabes da fronteira é a $1^{a}$ Suruta do Alcorão Al-Fatiha (Abertura). A Tabela 01 mostra a $1^{\text {a }}$ Suruta, à esquerda em árabe e à direita em português. A oração é composta por sete versículos.

Além disso, existe a prática do Ramadã, que significa o jejum que consiste em absterse deste o raiar do sol até o pôr-do-sol esse ritual tem a duração de um mês e acontece no nono mês do calendário islâmico, pois nesse mês o alcorão foi revelado ao Profeta Maomé através de Deus, que para os mulçumanos é chamado de Alá, nos dias de Ramadã os mulçumanos tem fazeres extras em relação às rezas que praticam como, por exemplo, a 
oração do tarawith que são orações especificas do Ramadã e são praticadas a noite depois da última oração que é obrigatória, conforme os cinco pilares do islam.

Tabela 01: Tradução da $1^{\text {a }}$ Suruta do Alcorão Al-Fatiha.

\begin{tabular}{|c|c|}
\hline Em Árabe (Original): & Em português: \\
\hline 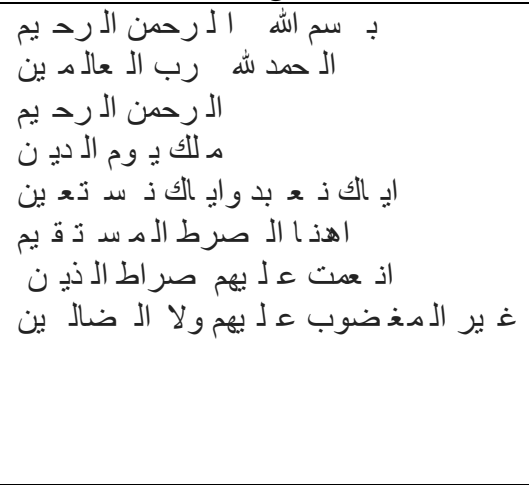 & $\begin{array}{l}\text { 1.Em nome de Deus, o Clemente, o } \\
\text { Misericordioso. } \\
\text { 2.Louvado seja Deus, Senhor do Universo, } \\
\text { 3. Clemente, o Misericordioso, } \\
\text { 4. Soberano do Dia do Juízo. } \\
\text { 5.Só a Ti adoramos e só de Ti imploramos } \\
\text { ajuda! } \\
\text { 6. Guia-nos à senda reta, } \\
\text { 7.À senda dos que agraciaste, não à dos } \\
\text { abominados, nem à dos extraviados. }\end{array}$ \\
\hline
\end{tabular}

Fonte: Samir El Hayeh (1989).

Outro fazer do Ramadã é a prática da caridade que todos devem fazer conforme a situação financeira de cada pessoa que pode ser feita pela doação de alimentos e dinheiro, essa prática tem que ser realizado de preferência nos últimos dias do jejum, a pessoa que não se encontra em condições de realizar o jejum deve realizar durante esse mês do Ramadã a doação de um prato de alimento para cada dia do jejum.

Com a finalização do Ramadã no dia seguinte os mulçumanos comemoram o natal que se chama Eid Al Fitr no qual nesse dia as famílias se reúnem, almoçam e jantam juntas, realizam a oração específica do natal ao passar esse natal, depois de dois meses do Ramadã os mulçumanos comemoram outro natal que se chama Eid Al-Aldha .

Nesse natal os mulçumanos com condições financeiras devem comprar um ovelha e fazer o abate do modo islâmico e distribuir essa carne para família e também as pessoas economicamente desfavorecidas. A religiosidade é de suma importância para o sentimento de pertencimento delas e de suas manifestações culturais, para que elas possam se expressar com as práticas de seus rituais.

\subsection{Gastronomia}

A questão da culinária árabe também se manteve presente no local de imigração, com a realização e elaboração de pratos árabes. Os depoentes se dispuseram a contribuir com a pesquisa através da preparação de um dos pratos típicos que são elaborados por familiares de árabes em Jaguarão. 
A Figura 03 é o Mahmoul um prato árabe feito principalmente nos natais. É feito com tâmara como recheio principal, e farinha de semolina para a elaboração da massa.

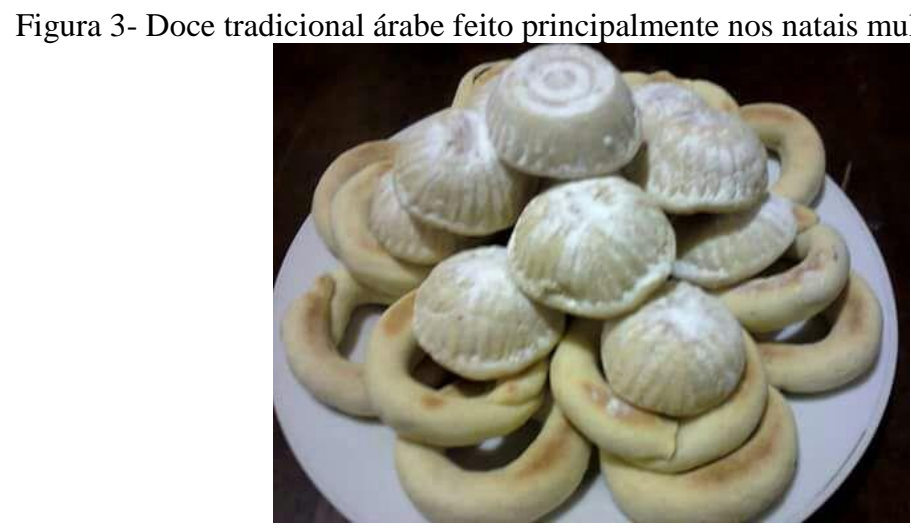

Fonte: Da autora Dalal (2017).

Na Figura 04 temos a representação de um prato salgado que se chama Daaole esse prato é feito com a folha da uva e tem como recheio arroz e guisado e temperos como pimenta como principal ingrediente.

Figura 4- Daaole prato feito principalmente com a folha da uva.

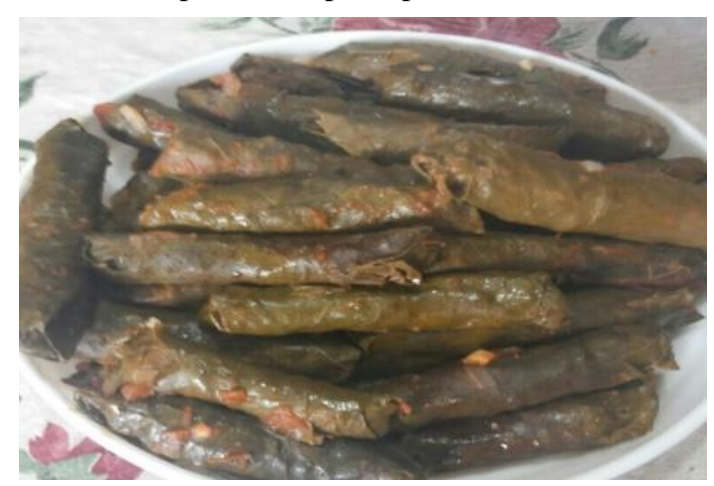

Fonte: Dalal, (2017)

\subsection{Indumentária}

A vestimenta árabe feminina é representada pelo hijab que é representado pelo lenço e também a abaia que representa um vestido longo, também faz parte do vestuário túnicas e calças largas. Na Figura 05 temos a representação da indumentária feminina árabe. Em relação ao vestuário masculino temos como representação do tarbush que representa um pequeno chapéu, e do dishdasha que representa uma roupa longa que geralmente são usadas por homens mais velhos. 
Figura 5- Representa a indumentária feminina árabe na fronteira.

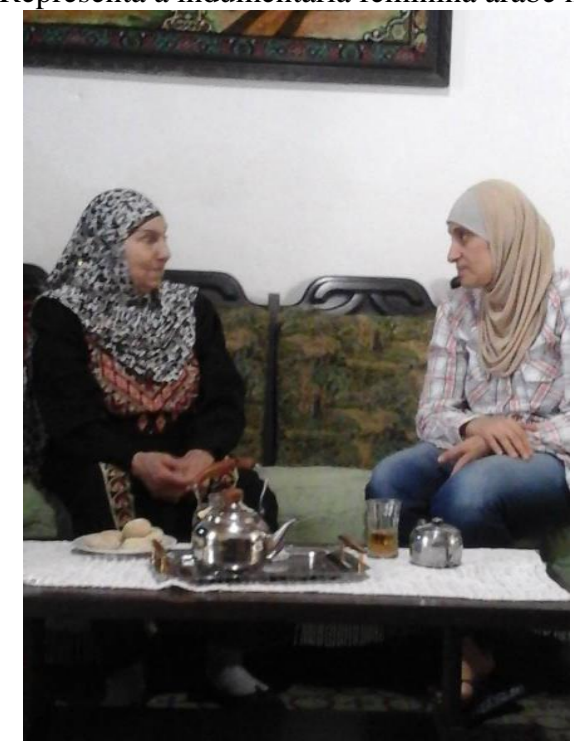

Fonte: Dalal ,(2017)

A questão do lenço no Islam vai além da indumentária feminina ele representa a identidade da mulher e sua proteção. E também o lenço além de representar a cultura, ele também representa a religião, onde no Alcorão temos a questão do uso do lenço mencionado na indumentária feminina.

Em relação a indumentária masculina, os mais tradicionais usam o dishdasha que significa uma vestimenta longa e o tarbush que acompanha a vestimenta que é reconhecido como chapéu que são usados por homens mais adeptos a cultura .

\section{Considerações finais}

Concluindo, pode-se afirmar que esse trabalho contribui para a manutenção da identidade e da memória da cultura árabe presente na fronteira. De certa forma, também pode servir para a valorização do turismo, ou seja, a autenticidade, o conhecimento destas expressões culturais é fundamental para os estudos culturais locais e para a história da fronteira. Entende-se que se deve pensar em espaços onde a cultura árabe possa ser contemplada, vivenciada, como em serviços de alimentação, em um restaurante árabe com a gastronomia típica desses povos traz um aspecto de representação e pertencimento a culinária árabe presente no local.

Os árabes marcaram suas atividades na fronteira desde os primeiros imigrantes que aqui vieram e desenvolveram o ofício de mascate. Dessa forma mesmo estando fora de sua terra natal esses povos organizam seu modo de vida a construção de suas culturas, ou seja, a criação de mesquitas, escolas islâmicas que ensinam a religião, a questão da celebração da 
cultura árabe e suas manifestações presentes na fronteira, fazendo com que esses povos tenham o sentimento de pertencimento em suas vidas mesmo não estando em seu país de origem.

Enfim a presença das atividades e cultura árabe na fronteira é fundamental para o conhecimento do patrimônio, memória e turismo e também para que as pessoas possam ter contato com outras culturas presentes na fronteira.

O registro dos bens culturais para a construção de uma cultura, de um patrimônio é fundamental para a construção de uma identidade e de uma memória e de seus aspectos imateriais presentes no local e na fala das pessoas que vivenciaram os fatos.

Os imigrantes enfrentam grandes desafios em suas imigrações tais como questão de aceitação e a questão do preconceito que algumas pessoas possuem aos imigrantes, também temos aspectos da cultura e da religiosidade presente no país de imigração que as vazes causa estranhamento da comunidade local. O estudo e a educação podem contribuir para a sociedade a questão do respeito as diferentes etnias, religiões e culturas presentes no local.

\section{Referências}

ASSMANN, Jan. Religion and Cultural Memory: ten studies. Califórnia: Stanford University Press, 2006.

CASTELlO, Iara Regina.; HAUSEN, Ênio Costa.; LEHNEN, Arno Carlos. et al. (org.). Práticas de Integração nas Fronteiras: temas para o MERCOSUL. Porto Alegre: Ed. da Universidade / UFRGS, Instituto Goethe / ICBA, 1995

HAYEH, Samir. Centro de Divulgação do Islam para a América Latina, São Paulo: Fambras, 1989.

MAZZEI, Enrique. Rivera (Uruguay) - Sant'Ana (Brasil): Identidad, território e integración fronteriza. Departamento de Sociologia da Universidad de la República, 2010.

SIMÃO, Maria Cristina Rocha. Preservação do Patrimônio Cultural em cidades, Belo Horizonte: Autêntica, 2006.

ASEFF, Liane Chipollino. Um olhar sobre a presença árabe na Fronteira. Estudios Historicos - CDHRPyB- Año VI - Julio 2014 - No 12 - ISSN: 1688 - 5317. Uruguay

Disponível em: http://www.estudioshistoricos.org/12/artigo\%20liane\%20chipollino\%20julio\%202014.pdf. Acesso em: 19. out.2017.

COSTA, Luciana.; GASTAL Suzana. Turismo e Paisagem Cultural: para Pensar o Transfronteiriço. São Paulo: Anptur, 2010.

Disponível em: http://www.anptur.org.br/ocs/index.php/seminario/2010/paper/view/609. Acesso em: 4.out.2017. 
FONSECA, Maria Cecília Londres. Referências Culturais: Base para novas políticas de patrimônio. In.: Revista Políticas Sociais - acompanhamento e análise nº 2, 2001. Disponível em: http://repositorio.ipea.gov.br/bitstream/11058/4775/1/bps_n.2_referencia_2.pdf. Acesso em 26.nov.2017.

HANNERZ, Ulf. Fluxos. Fronteiras, Híbridos: Palavras chave de uma antropologia transnacional. Cadernos Naui. Florianópolis,V. 01, n. 03, p. 07 - 39, set. 2010. Disponível em: http://www.scielo.br/pdf/mana/v3n1/2454.pdf. Acesso em: 4 .out.2017.

JARDIM, Denise Fagundes. Palestinos no Extremo Sul do Brasil. Identidade Étnica e os Mecanismos Sociais da Etnicidade. Chuí/RS, Rio de Janeiro. UFRG/PPGAS/MUSEU NACIONAL, 2000. Disponível em:

https://www.lume.ufrgs.br/bitstream/handle/10183/5249/000298770.pdf?sequence=1. Acesso em: 4.out.2017.

\section{Depoimentos:}

Sra.Khawla Daous. Duração: 1 min e 47 s. Jaguarão, 12/10/2017.

Sr.Radi Abu Saleh: Duração: 8 min e 29 s. Jaguarão, 08/10/2017. 